\title{
BMJ Open Prevalence of cigarette and waterpipe tobacco smoking among adults in three Eastern Mediterranean countries: a cross-sectional household survey
}

\author{
Rima Nakkash, ${ }^{1}$ Yousef Khader$^{2}$ Ali Chalak, ${ }^{3}$ Ruba Abla (D) , ${ }^{1}$ \\ Niveen M E Abu-Rmeileh, ${ }^{4}$ Aya Mostafa (1) , ${ }^{5}$ Mohammed Jawad (1) ,6 \\ Ji-Hyun Lee, ${ }^{7}$ Ramzi G Salloum (D) ${ }^{1,8}$
}

To cite: Nakkash R, Khader Y, Chalak A, et al. Prevalence of cigarette and waterpipe tobacco smoking among adults in three Eastern Mediterranean countries: a cross-sectional household survey. BMJ Open 2022;12:e055201. doi:10.1136/ bmjopen-2021-055201

- Prepublication history and additional supplemental material for this paper are available online. To view these files, please visit the journal online (http://dx.doi.org/10.1136/ bmjopen-2021-055201).

Received 05 July 2021 Accepted 06 January 2022

Check for updates

(C) Author(s) (or their employer(s)) 2022. Re-use permitted under CC BY-NC. No commercial re-use. See rights and permissions. Published by BMJ.

For numbered affiliations see end of article.

Correspondence to

Dr Rima Nakkash;

rn06@aub.edu.lb

\section{ABSTRACT}

Objectives Tobacco smoking is on the rise in the Eastern Mediterranean region. In light of limited surveillance of smoking in the region, this study sought to understand the prevalence of cigarette and waterpipe smoking among adults and the factors associated with smoking in Lebanon, Jordan and Palestine (West Bank only).

Design, setting and participants Household surveys were conducted with participants over the age of 18 in Lebanon $(n=1680)$, Jordan $(n=1925)$ and Palestine $(n=1679)$ between June and August 2019. A multistage cluster sampling approach with probability-proportionalto-size random selection method was followed in the three countries.

Primary and secondary outcome measures Genderspecific prevalence rates for cigarette and waterpipe smoking were estimated. Multivariable logistic regression was used to examine factors associated with current cigarette and waterpipe tobacco smoking.

Results The prevalence of cigarette smoking among males and females respectively was $48.6 \%$ and $21.5 \%$ in Lebanon, $50.4 \%$ and $9.1 \%$ in Jordan, and $53.4 \%$ and $3.1 \%$ in Palestine. The prevalence of waterpipe smoking among males and females respectively was $32.7 \%$ and $46.2 \%$ in Lebanon, $13.4 \%$ and $7.8 \%$ in Jordan, and $18.0 \%$ and $7.9 \%$ in Palestine. Cigarette smokers were significantly $(p<0.05)$ more likely to be male, younger and with lower educational attainment across the three countries. Waterpipe smokers were more likely to be young adults across the three countries $(p<0.001)$. They were more likely to be male in Jordan and Palestine, and more likely to be female in Lebanon.

Conclusions The high prevalence rates of smoking in Lebanon, Jordan and Palestine are concerning. Continued surveillance is key to monitor smoking patterns and inform stronger tobacco control measures.

\section{INTRODUCTION}

Smoking is the leading cause of preventable death as well as a main risk factor for cancer, cardiovascular and pulmonary diseases. Although considerable progress has been achieved in curbing the tobacco epidemic
Strengths and limitations of this study

- The study reports contemporary estimates of smoking prevalence using large, nationally representative surveys, which have been consistently lacking in previous studies.

- The study used standardised questionnaires across the three countries, allowing for valid cross-country comparisons.

- Tobacco use was self-reported and not biochemically verified and only a small number of females reported current smoking in Jordan and Palestine, which may have under-reported prevalence.

- The study did not report on use of other alternative smoking products which are increasingly more available in the loosely regulated markets of those countries.

in many parts of the world, smoking trends continue to increase in low-income and middle-income countries. ${ }^{1}$ One notable example has been the Eastern Mediterranean region (EMR)-which the World Health Organization (WHO) has projected the smoking prevalence to increase by $2025 .^{2}$ Cigarette smoking is highly prevalent in the EMR, due to weak regulatory environments, insufficient surveillance infrastructure and interference from a strong tobacco industry. ${ }^{3}$ The problem is compounded by the wide prevalence of waterpipe tobacco smoking. ${ }^{4}$ Waterpipe smoking rates in the region are considered the highest worldwide, with notably high prevalence among young adults. ${ }^{5}$ This pattern is attributed to multiple factors, including the perception of waterpipe smoking as a less harmful alternative to cigarette smoking, the café culture encouraging social smoking of the waterpipe and appeal of flavoured waterpipe tobacco. ${ }^{6}$ 
The WHO Framework Convention on Tobacco Control (FCTC) requires parties to collect data on tobacco use and exposure on a regular basis to monitor smoking trends and policy implementation. ${ }^{8}$ To date, surveillance of tobacco use among adults in the EMR has been limited. For example, routinely available data from the Global Adult Tobacco Survey (GATS) are only available in Egypt (2009), ${ }^{9}$ Qatar (2013) ${ }^{10}$ and Pakistan (2014). ${ }^{11}$ Other surveillance efforts in the region have been limited to specific populations, such as youth, ${ }^{12}$ university students, ${ }^{1314}$ and healthcare professionals. ${ }^{15}$ These limitations in the available smoking prevalence data justify the need for detailed national prevalence data on both cigarette and waterpipe smoking among adults in Eastern Mediterranean countries.

In Lebanon, the most recent national estimates for adult cigarette smoking date back to $2013^{2}$ when the prevalence of current cigarette smoking was $34 \%$ among males and 19\% among females. The national estimates for waterpipe tobacco smoking prevalence $(25.3 \%)$ date back to 2009 , when the prevalence rate was $26.5 \%$ among males and $24.3 \%$ among females. ${ }^{16}$ According to Jordans WHO STEPwise Approach to NCD Risk Factor Surveillance (STEPS) 2019 survey, $65.3 \%$ of men and $16.4 \%$ of women were current smokers of any tobacco products. ${ }^{17}$ As for Palestine, the most recent national estimates were from the Palestinian Family Survey in 2010, when the prevalence rate for cigarette smoking was $29.9 \%$ among adults (49.7\% among men and $3.5 \%$ among women). ${ }^{18}$

Given that the most recent national prevalence estimates across the three countries date back to one decade, this study sought to estimate contemporary prevalence rates of current cigarette and waterpipe smoking in Lebanon, Jordan and Palestine (West Bank only) and their correlates. Further, the issue of dual tobacco use has not been sufficiently explored in studies coming from the region, and as such, this study examined the dual use of cigarette and waterpipe tobacco in these three countries.

\section{METHODS}

\section{Data source}

We conducted nationally representative in-person crosssectional household surveys in Lebanon, Jordan and Palestine between June and August 2019. Eligible respondents included males and females aged 18 years and older, residing in each of the countries as their primary place of residence, regardless of nationality.

The sample size was calculated to estimate the prevalence of current waterpipe smoking for males and females in each country based on previously reported prevalence rates $^{2} 19$ with a margin of error of $5 \%$ if the prevalence rate is more than $10 \%$ or with a margin of error of half of the assumed prevalence if it is less than $10 \%$. The average number of individuals or households sampled per cluster and the design effect were taken into consideration. A design effect of 2.0 was used based on the recommendations of the GATS manual. With an $80 \%$ power and $\alpha=0.05$, the minimum number of clusters needed in the countries ranged from 16 to 28 and the number of subjects ranged from 480 to 840 persons. Since one male and one female were to be selected from each household, the largest number of clusters and households (28 clusters and 1680 subjects; 840 men and 840 women) was the sample size for each country.

A multistage cluster sampling approach with probabilityproportional-to-size random selection method was followed. In each country, the sample of households was chosen in two stages. First, well-defined clusters were selected within each governorate (ie, province). Second, housing units were selected within each selected cluster. The sampling frame for clusters was specific to the characteristics of each country. In Lebanon, all eight governorates were selected for sampling: Akkar, BaalbekHermel, Bekaa, Beirut, Mount Lebanon, Nabatieh, North Lebanon and South Lebanon. In Jordan, all 12 governorates were included in the study: Ajloun, Amman, Aqaba, Balqa, Irbid, Jerash, Karak, Ma'an, Madaba, Mafraq, Tafilah and Zarqa. In Palestine, all 11 governorates of the West Bank were selected: Bethlehem, East Jerusalem, Hebron, Jenin, Qalqilya, Nablus, Ramallah and Al-Bireh, Jericho, Salfit, Tubas and Tulkarm. The Palestinian governorates in Gaza were excluded due to logistical barriers. The second stage of household selection involved choosing a random sample of 30 households from a complete list of households in a selected area, based on local administrative sources or household lists from the most recent census. One eligible male and one female resident, who consider the site of data collection as their primary place of residence, were selected from each selected household. In Lebanon and Palestine, if an eligible female or male was not available for interview at the time of household visit, additional households were selected until an equal number of males and females was reached. In Jordan, additional households were selected that yielded a higher number of males than females. After eligibility screening, we provided potential respondents with information about the study and asked them to provide verbal consent to participate as per IRB approval. With the exception of aforementioned respondent selection, the same methods and recruitment protocol were used in all three countries.

\section{Data collection}

Data were collected using the same structured, Arabiclanguage questionnaire, with selected questions tailored to local context for each country. In the three countries, the surveys were administered face to face by trained interviewers. Prior to data collection, each country team pretested the questionnaires with 10-15 individuals of similar characteristics to that of the survey respondents. Minor amendments to wordings of a few questions were applied. Each country team then piloted with 10-15 individuals before data collection proceeded. No changes following piloting were needed. Data collectors in the three countries were trained on the ethics of data 
collection, consenting, sampling methodology and on the survey questions, using the same training manual. The training included a review of each questionnaire item, followed by practice sessions which involved role play as interviewer and interviewee which focused on probing to make sure all interviewees give full answers to ensure that there is no missing data for the analysis. It is important to note that the missing data are minimal $(<1 \%)$ because of the quality control and assurance procedures implemented.

\section{Measures}

Respondents were asked if they had ever tried cigarettes or waterpipe tobacco. Among ever users of each product, respondents were asked if they were current users of the product. Current cigarette smoking was defined as currently smoking cigarettes every day or some days. Similarly, current waterpipe smoking was defined as currently smoking tobacco in a waterpipe every day or some days. Among current cigarette smokers, respondents were asked about the number of cigarettes smoked per day. Dual current smokers included both cigarette and waterpipe smokers while any current smoker included cigarette or waterpipe smokers. Among current waterpipe tobacco smokers, respondents were asked about the number of waterpipe sessions they smoked at home per week, the number of waterpipe sessions they smoked in a café per week, and whether they usually smoked flavoured waterpipe tobacco. We assessed the demographic characteristics of respondents, including their sex, age in years, marital status, educational attainment and household monthly income. The survey instrument can be found as online supplemental material.

\section{Statistical analysis}

Descriptive statistics were used to summarise the study participants' demographic and socio-economic characteristics. We estimated overall gender-specific prevalence rates of cigarettes and waterpipe smoking and their $95 \%$ CIs within each country. For the purpose of calculation of age-standardised prevalence rates, the WHO World Standard Population which reflects the average age structure of the world's population expected over the next generation, from 2000 to 2025 was used..$^{20}$ Multivariable logistic regression analysis was conducted to examine factors associated with current cigarette smoking and current waterpipe smoking in separate models for each country. The independent variables tested in these models included gender (female vs male), age group in years (18-29, $30-49,50-64$ and 65 or older), educational attainment (primary school or less, middle school, high school/ diploma and university), marital status (ever married vs never married) and individual monthly income (quartiles within each country). ORs and their 95\% CIs were estimated from the models. A p value of less than 0.05 was considered statistically significant. Respondents with missing data on outcome measures or covariates were excluded from models on a casewise basis. Data were analysed using Stata statistical software V.16 (StataCorp).

\section{Patient and public involvement}

There was no patient public involvement in the design, conduct, reporting or dissemination plans of our research.

\section{RESULTS}

A total of 1680 respondents in Lebanon, 1925 in Jordan, and 1679 in Palestine completed the surveys. The number of non-respondents (rate) was $862(33.9 \%)$ in Lebanon, $74(3.7 \%)$ in Jordan and $141(7.7 \%)$ in Palestine.

Table 1 presents the characteristics of respondents by gender in each country. Females represented $50.0 \%$ of the sample in Lebanon, $44.6 \%$ in Jordan and $50.0 \%$ in Palestine. Almost $45.1 \%$ of respondents in Lebanon, $45.9 \%$ of respondents in Jordan, and $41.3 \%$ of respondents in Palestine were younger than 50 years old. The majority $(80.8 \%)$ of respondents in Lebanon, $75 \%$ of respondents in Jordan and $81.5 \%$ of respondents in Palestine were ever married. Almost one-fifth $(20.7 \%)$ of respondents in Lebanon, $25.1 \%$ in Jordan and $16.2 \%$ in Palestine had completed university education.

\section{Prevalence of cigarette and waterpipe tobacco smoking}

Table 2 shows the crude and age-standardised prevalence rates of current cigarette smoking, current waterpipe smoking, dual smoking and any smoking, by country. Overall, the crude prevalence rate $(95 \%$ CI ) for current cigarette smoking was $35.1 \%(32.8 \%$ to $37.4 \%)$ in Lebanon, $32.0 \%$ (29.9\% to $34.1 \%$ ) in Jordan and $28.2 \%$ $(26.1 \%$ to $30.5 \%)$ in Palestine. The prevalence rate for current waterpipe smoking was $39.5 \%$ ( $37.1 \%$ to $41.8 \%$ ) in Lebanon, $11.0 \%$ (9.6\% to $12.4 \%$ ) in Jordan and $12.9 \%$ (11.4\% to $14.6 \%)$ in Palestine. The overall rate for dual current smoking was $3.6 \%$ (2.8\% to $4.6 \%$ ) in Lebanon, $2.8 \%(2.1 \%$ to $3.6 \%)$ in Jordan and $4.4 \%$ (3.5\% to $5.5 \%$ ) in Palestine. As for any current smoking, the prevalence rate was $70.9 \%(68.7 \%$ to $73.1 \%)$ in Lebanon, $40.2 \%$ (38.0\% to $42.4 \%)$ in Jordan and $36.7 \%$ (34.4\% to $39.1 \%)$ in Palestine. Respectively, the age-standardised prevalence rates of current cigarette and waterpipe smoking were $27.8 \%$ and $38.1 \%$ in Lebanon, $25.5 \%$ and $12.0 \%$ in Jordan, and $26.3 \%$ and $14.1 \%$ in Palestine.

\section{Patterns of cigarette and waterpipe smoking}

Table 3 presents the patterns of cigarette and waterpipe smoking among current smokers according to gender and country. In Lebanon, almost half of current cigarette smokers reported smoking $\geq 20$ cigarettes per day ( $42.6 \%$ of males and $51.9 \%$ of females). In Jordan, more than half of male current cigarette smokers $(52.0 \%)$ and one third of female cigarette smokers $(33.3 \%)$ reported smoking $\geq 20$ cigarettes per day. In Palestine, among those who currently smoke cigarettes, $37.5 \%$ of males and $3.8 \%$ of females reported smoking $\geq 20$ cigarettes per day. 
Table 1 Sociodemographic characteristics by gender and country 2019

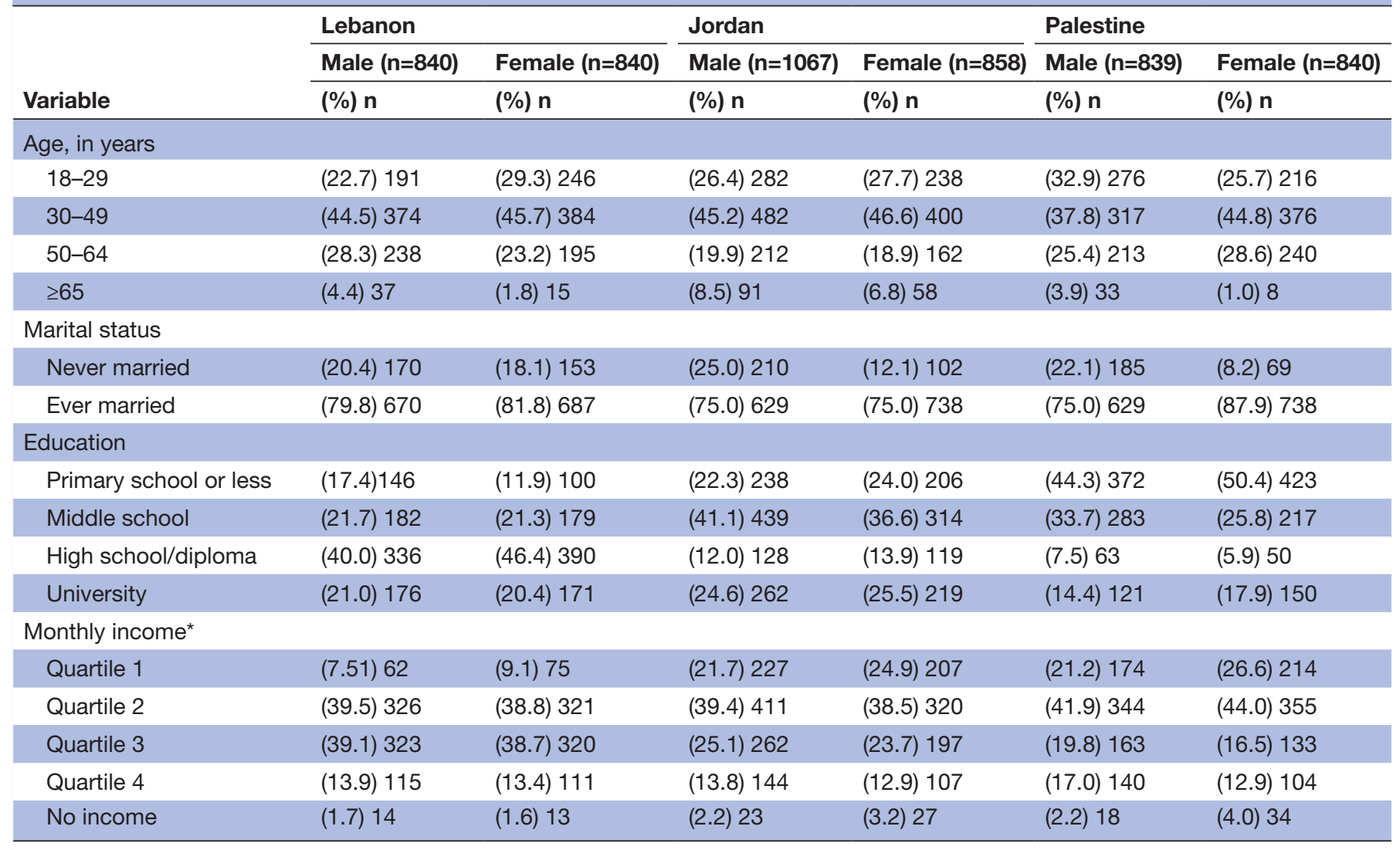

*Income quartile levels: Lebanon: (1) <US529.88; (2) US\$529.88 to <US\$993.53; (3) US\$993.53 to <US \$1987.05; (4) $\geq$ US\$1987.05. Jordan: (1) < US\$423.13; (2) US\$423.13 = <US\$705.22; (3) US\$705.22 to <US\$1269.39. Palestine: (1) < US\$610.04; $\$ 610.04$ to $<$ US\$1067.57; (3) US\$1067.57 to <US\$1525.10; (4) $\geq$ US1525.10.

The majority of waterpipe smokers in Lebanon used flavoured tobacco $(86.2 \%$ of males and $89.2 \%$ of females $)$, smoked more than three sessions at home $(92.5 \%$ of males and $86.9 \%$ of females) and smoked three sessions or less per week in a café $(90.0 \%$ of males and $96.3 \%$ of females). In Jordan, the majority of waterpipe smokers used flavoured tobacco $(92.3 \%$ of males and $98.5 \%$ of females), the majority of male respondents $(70.5 \%)$ and less than half of females $(46.9 \%)$ smoked more than three waterpipe sessions at home, and the majority of respondents smoked three sessions or less per week in a café $(62.9 \%$ of males and $85.7 \%$ of females). In Palestine, the majority of waterpipe smokers used flavoured tobacco $(94.6 \%$ of males and $93.9 \%$ of females), $85.7 \%$ of males and $95.4 \%$ of females smoked more than 3 sessions of waterpipe at home, and $97.7 \%$ of males and $95.5 \%$ of females smoked three sessions or less per week in a café.

\section{Factors associated with current cigarette smoking}

Table 4 presents the results of the multivariable analysis of factors associated with current cigarette smoking by country and the adjusted OR. In Lebanon, males were more likely than females to be current cigarette smokers (OR 5.07; 95\% CI 3.73 to 6.89). Compared with young adults 18-29 years old, respondents who were older were more likely to be current smokers: (OR 5.52; 95\% CI 3.22 to 9.49 ) among those $30-49$ years old, (OR 6.34; $95 \%$ CI 3.57 to 11.26 ) among adults 50-64 years old and (OR 2.84; $95 \%$ CI 1.15 to 7.05 ) among adults $\geq 65$ years old. Compared with adults who had a primary school education or less, adults with a high school education (OR 0.44; $95 \%$ CI 0.27 to 0.72 ) and those with a university education (OR $0.52 ; 95 \%$ CI 0.29 to 0.92 ) were significantly less likely to be current cigarette smokers.

In Jordan, males were significantly more likely than females to be current cigarette smokers (OR 13.77; $95 \%$ CI 9.29 to 20.44 ). Adults $\geq 65$ years old were less likely than those 18-29 years old to be current cigarette smokers (OR $0.35 ; 95 \%$ CI 0.19 to 0.65$)$. Compared with adults who had a primary school education or less, adults with a high school education (OR:0.61; 95\% CI 0.38 to 0.97 ) and those with a university education (OR $0.61 ; 95 \%$ CI 0.41 to 0.91 ) were less likely to be current cigarette smokers. In addition, adults in the highest income quartile were significantly more likely to be current smokers compared with adults in the lowest income quartile (OR 1.68; $95 \%$ CI 1.05 to 2.69 ).

Finally, in Palestine, males were also significantly more likely than females to be current cigarette smokers (OR 66.95 ; $95 \%$ CI 29.28 to 153.10$)$. Adults $\geq 65$ years old were less likely than those 18-29 years old to be cigarette 
Table 2 Crude and age-standardised prevalence rates (ASR) and their $95 \% \mathrm{Cl}$ of current cigarette smoking, current waterpipe smoking, dual smoking and any smoking in Lebanon, Jordan and Palestine, 2019

\begin{tabular}{|c|c|c|c|c|c|c|c|c|}
\hline \multirow[b]{2}{*}{$\begin{array}{l}\text { Country/ } \\
\text { gender }\end{array}$} & \multicolumn{2}{|c|}{ Current cigarette smoking } & \multicolumn{2}{|c|}{ Current waterpipe smoking } & \multicolumn{2}{|c|}{ Dual smoking } & \multicolumn{2}{|l|}{ Any smoking } \\
\hline & $\begin{array}{l}\text { Crude } \\
(95 \% \mathrm{Cl})\end{array}$ & $\begin{array}{l}\text { ASR } \\
(95 \% \mathrm{CI})\end{array}$ & $\begin{array}{l}\text { Crude } \\
(95 \% \mathrm{Cl})\end{array}$ & $\begin{array}{l}\text { ASR } \\
(95 \% \mathrm{CI})\end{array}$ & $\begin{array}{l}\text { Crude } \\
(95 \% \mathrm{Cl})\end{array}$ & $\begin{array}{l}\text { ASR } \\
(95 \% \mathrm{CI})\end{array}$ & $\begin{array}{l}\text { Crude } \\
(95 \% \mathrm{Cl})\end{array}$ & $\begin{array}{l}\text { ASR } \\
(95 \% \mathrm{Cl})\end{array}$ \\
\hline \multicolumn{9}{|l|}{ Lebanon } \\
\hline Male & $\begin{array}{l}48.6 \\
(45.1 \text { to } 52.0)\end{array}$ & $\begin{array}{l}38.6 \\
(30.9 \text { to } 46.4)\end{array}$ & $\begin{array}{l}32.7 \\
(29.6 \text { to } 36.0)\end{array}$ & $\begin{array}{l}35.6 \\
(26.4 \text { to } 44.7)\end{array}$ & $\begin{array}{l}5.5 \\
(4.0 \text { to } 7.2)\end{array}$ & $\begin{array}{l}5.8 \\
(2.1 \text { to } 9.6)\end{array}$ & $\begin{array}{l}75.8 \\
(72.8 \text { to } 78.7)\end{array}$ & $\begin{array}{l}68.4 \\
(57.0 \text { to } 79.8)\end{array}$ \\
\hline Female & $\begin{array}{l}21.5 \\
\text { (18.8 to } 24.5)\end{array}$ & $\begin{array}{l}15.9 \\
(11.3 \text { to } 20.5)\end{array}$ & $\begin{array}{l}46.2 \\
\text { (42.8 to } 49.6)\end{array}$ & $\begin{array}{l}39.8 \\
\text { (29.4 to } 50.3 \text { ) }\end{array}$ & $\begin{array}{l}1.8 \\
\text { (1.0 to } 2.9)\end{array}$ & $\begin{array}{l}0.9 \\
(0.4 \text { to } 1.3)\end{array}$ & $\begin{array}{l}66.0 \\
(62.6 \text { to } 69.2)\end{array}$ & $\begin{array}{l}54.9 \\
\text { (43.5 to } 66.3 \text { ) }\end{array}$ \\
\hline Total & $\begin{array}{l}35.1 \\
\text { (32.8 to } 37.4 \text { ) }\end{array}$ & $\begin{array}{l}27.8 \\
(22.9 \text { to } 32.6)\end{array}$ & $\begin{array}{l}39.5 \\
\text { (37.1 to } 41.8 \text { ) }\end{array}$ & $\begin{array}{l}38.1 \\
\text { (31.2 to } 44.9)\end{array}$ & $\begin{array}{l}3.6 \\
(2.8 \text { to } 4.6)\end{array}$ & $\begin{array}{l}3.6 \\
(1.4 \text { to } 5.7)\end{array}$ & $\begin{array}{l}70.9 \\
(68.7 \text { to } 73.1)\end{array}$ & $\begin{array}{l}62.3 \\
(54.1 \text { to } 70.4)\end{array}$ \\
\hline \multicolumn{9}{|l|}{ Jordan } \\
\hline Male & $\begin{array}{l}50.4 \\
\text { (47.4 to } 53.5)\end{array}$ & $\begin{array}{l}39.7 \\
(32.9 \text { to } 46.4)\end{array}$ & $\begin{array}{l}13.5 \\
(11.5 \text { to } 15.7)\end{array}$ & $\begin{array}{l}15.1 \\
\text { (9.4 to 20.7) }\end{array}$ & $\begin{array}{l}4.3 \\
(3.2 \text { to } 5.7)\end{array}$ & $\begin{array}{l}4.6 \\
\text { (1.6 to } 7.6)\end{array}$ & $\begin{array}{l}59.6 \\
\text { (56.6 to 62.6) }\end{array}$ & $\begin{array}{l}50.1 \\
\text { (41.9 to } 58.3 \text { ) }\end{array}$ \\
\hline Female & $\begin{array}{l}9.1 \\
\text { (7.3 to } 11.2)\end{array}$ & $\begin{array}{l}8.0 \\
(4.2 \text { to } 11.8)\end{array}$ & $\begin{array}{l}7.8 \\
(6.1 \text { to } 9.8)\end{array}$ & $\begin{array}{l}8.3 \\
\text { (3.8 to } 12.9)\end{array}$ & $\begin{array}{l}0.8 \\
(0.3 \text { to } 1.7)\end{array}$ & $\begin{array}{l}0.5 \\
(0.1 \text { to } 0.9\end{array}$ & $\begin{array}{l}16.1 \\
(13.7 \text { to } 18.7)\end{array}$ & $\begin{array}{l}15.9 \\
(10.0 \text { to } 21.8)\end{array}$ \\
\hline Total & $\begin{array}{l}32.0 \\
(29.9 \text { to } 34.1)\end{array}$ & $\begin{array}{l}25.5 \\
(21.4 \text { to } 29.6)\end{array}$ & $\begin{array}{l}11.0 \\
(9.6 \text { to } 12.4)\end{array}$ & $\begin{array}{l}12.0 \\
(8.3 \text { to } 15.7)\end{array}$ & $\begin{array}{l}2.8 \\
(2.1 \text { to } 3.6)\end{array}$ & $\begin{array}{l}2.8 \\
(1.1 \text { to } 4.4)\end{array}$ & $\begin{array}{l}40.2 \\
(38.0 \text { to } 42.4)\end{array}$ & $\begin{array}{l}34.8 \\
(29.6 \text { to } 40.0)\end{array}$ \\
\hline \multicolumn{9}{|l|}{ Palestine } \\
\hline Male & $\begin{array}{l}53.4 \\
(50.0 \text { to } 56.8)\end{array}$ & $\begin{array}{l}45.0 \\
(37.5 \text { to } 52.6)\end{array}$ & $\begin{array}{l}18.0 \\
\text { (15.5 to } 20.8)\end{array}$ & $\begin{array}{l}16.6 \\
\text { (11.5 to } 21.7)\end{array}$ & $\begin{array}{l}8.0 \\
(6.2 \text { to } 10.0)\end{array}$ & $\begin{array}{l}6.4 \\
\text { (3.5 to } 9.2)\end{array}$ & $\begin{array}{l}63.4 \\
(60.0 \text { to } 66.7)\end{array}$ & $\begin{array}{l}55.3 \\
\text { (46.6 to 63.9) }\end{array}$ \\
\hline Female & $\begin{array}{l}3.1 \\
(2.0 \text { to } 4.5)\end{array}$ & $\begin{array}{l}1.6 \\
\text { (1.0 to } 2.3)\end{array}$ & $\begin{array}{l}7.9 \\
(6.1 \text { to } 9.9)\end{array}$ & $\begin{array}{l}12.2 \\
(4.6 \text { to } 19.9)\end{array}$ & $\begin{array}{l}0.8 \\
(0.3 \text { to } 1.7)\end{array}$ & $\begin{array}{l}0.5 \\
(0.1 \text { to } 0.9)\end{array}$ & $\begin{array}{l}10.1 \\
(8.2 \text { to } 12.4)\end{array}$ & $\begin{array}{l}13.4 \\
\text { (5.7 to } 21.0)\end{array}$ \\
\hline Total & $\begin{array}{l}28.2 \\
(26.1 \text { to } 30.5)\end{array}$ & $\begin{array}{l}26.3 \\
(21.2 \text { to } 31.4)\end{array}$ & $\begin{array}{l}12.9 \\
(11.4 \text { to } 14.6)\end{array}$ & $\begin{array}{l}14.1 \\
(9.9 \text { to } 18.2)\end{array}$ & $\begin{array}{l}4.4 \\
(3.5 \text { to } 5.5)\end{array}$ & $\begin{array}{l}3.8 \\
(2.0 \text { to } 5.7)\end{array}$ & $\begin{array}{l}36.7 \\
\text { (34.4 to } 39.1 \text { ) }\end{array}$ & $\begin{array}{l}36.5 \\
\text { (30.3 to } 42.8)\end{array}$ \\
\hline
\end{tabular}

smokers (OR 0.33; 95\% CI 0.12 to 0.88 ). Compared with adults with a primary school education or less, adults with a middle school education (OR $0.58 ; 95 \%$ CI 0.39 to 0.84 ) and those with a university education (OR $0.57 ; 95 \%$ CI 0.35 to 0.93 ) were significantly less likely to be current cigarette smokers.
Factors associated with current waterpipe tobacco smoking

Table 5 presents the results of multivariable analysis of factors associated with current waterpipe tobacco smoking by country and the adjusted OR. In Lebanon, males were less likely than females to be current waterpipe smokers (OR 0.49; $95 \%$ CI 0.37 to 0.64$)$. In addition, adults older than 18-29 years old

Table 3 Patterns of cigarette and waterpipe smoking among current smokers according to gender by country in 2019

\begin{tabular}{|c|c|c|c|c|c|c|}
\hline \multirow[b]{3}{*}{ Variable } & \multicolumn{2}{|l|}{ Lebanon } & \multicolumn{2}{|l|}{ Jordan } & \multicolumn{2}{|l|}{ Palestine } \\
\hline & Males & Females & Males & Females & Males & Females \\
\hline & $(\%) n$ & $(\%) n$ & $(\%) n$ & $(\%) n$ & $(\%) n$ & $(\%) n$ \\
\hline \multicolumn{7}{|c|}{ Cigarettes per day } \\
\hline$<10$ & (35.0) 143 & (34.8) 63 & (3.4) 18 & $(18.0) 14$ & (9.4) 42 & $(23.1) 6$ \\
\hline $10-20$ & (42.6) 174 & (51.9) 94 & (44.6) 240 & (48.7) 38 & (53.1) 238 & (73.1) 19 \\
\hline$>20$ & (22.3) 91 & (13.3) 24 & (52.0) 280 & (33.3) 26 & (37.5) 168 & (3.8) 1 \\
\hline Total & (100.0) 408 & (100.0) 181 & (100.0) 538 & (100.0) 78 & (100.0) 448 & (100.0) 26 \\
\hline \multicolumn{7}{|c|}{ Waterpipe sessions at home, per week } \\
\hline$\leq 3$ & (7.5) 19 & (13.1) 49 & $(29.5) 33$ & $(53.1) 34$ & (85.7) 108 & $(95.4) 62$ \\
\hline$>3$ & (92.5) 234 & (86.9) 326 & $(70.5) 79$ & $(46.9) 30$ & (14.3) 18 & (4.6) 3 \\
\hline \multicolumn{7}{|c|}{ Waterpipe sessions at café, per week } \\
\hline$\leq 3$ & (90.9) 180 & (96.3) 236 & (62.9) 22 & $(85.7) 6$ & (97.7) 85 & (95.5) 21 \\
\hline$>3$ & (9.1) 18 & (3.7) 9 & $(37.1) 13$ & (14.3) 1 & (2.3) 2 & (4.5) 1 \\
\hline \multicolumn{7}{|c|}{ Type of waterpipe tobacco smoked } \\
\hline Flavoured & (86.2) 237 & (89.2) 346 & (92.3) 132 & $(98.5) 66$ & (94.6) 141 & (93.9) 62 \\
\hline Non-flavoured & (13.8) 38 & (10.8) 42 & (7.7) 11 & (1.5) 1 & (5.4) 8 & (6.1) 4 \\
\hline
\end{tabular}


Table 4 Multivariable analysis of factors associated with current cigarette smoking among adults by country in 2019

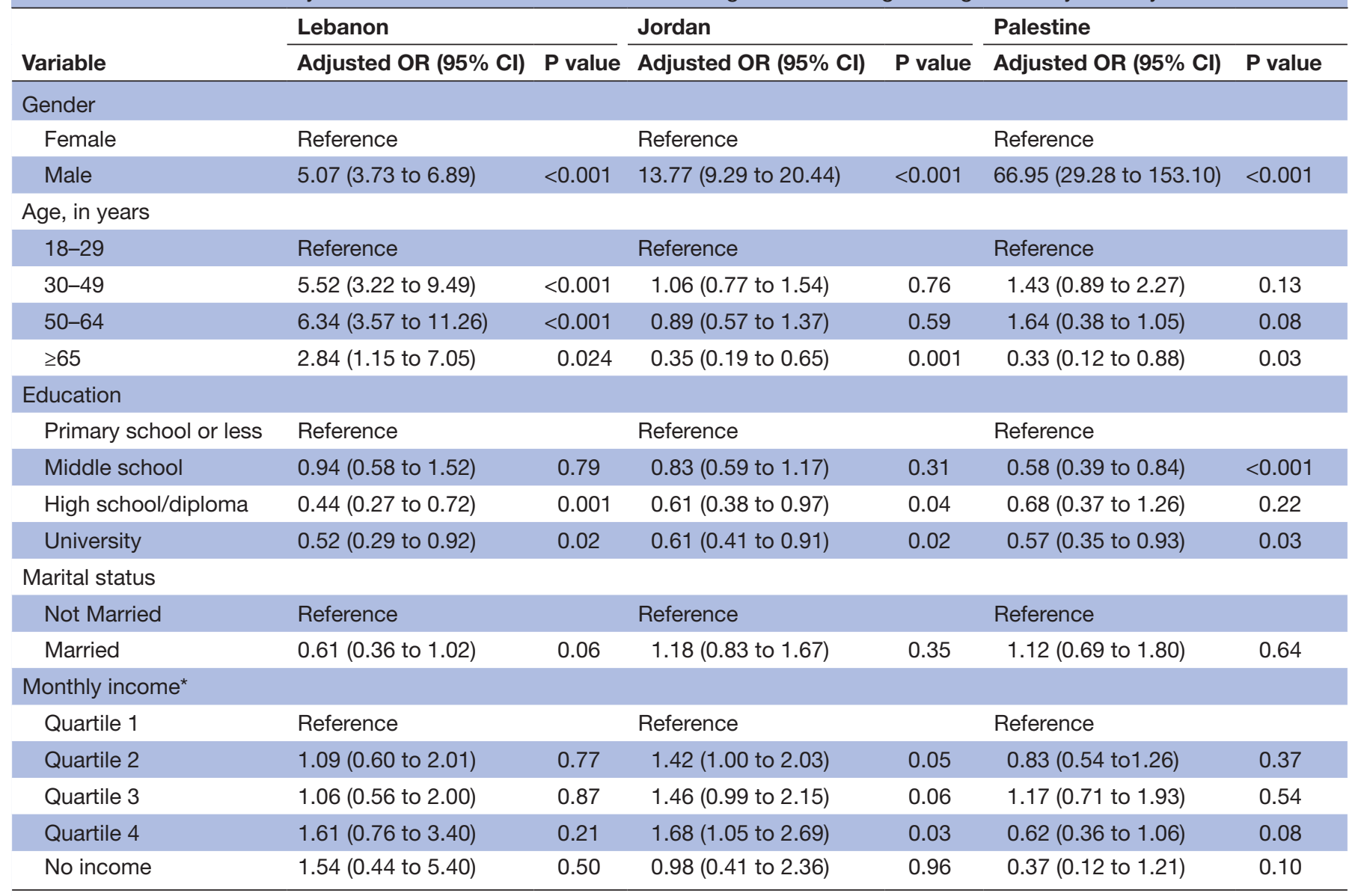

*Income quartile levels: Lebanon: (1) <US\$529.88; (2) US\$529.88 to <US\$993.53; (3) US\$993.53 to <US\$1,987.05; (4) >US\$1987.05. Jordan: (1) <US\$423.13; (2) US\$423.13 = <US\$705.22; (3) US\$705.22 to <US\$1269.39. Palestine: (1) <US\$610.04; US\$610.04 to $<$ US\$1067.57; (3) US\$1067.57 to <US\$1525.10; (4) $\geq$ US\$1525.10.

were less likely to be current waterpipe smokers: (OR 0.30 ; $95 \%$ CI 0.18 to 0.49 ) among $30-49$ years old (OR $0.08 ; 95 \%$ CI 0.04 to 0.15 ) among $50-64$ years old, and (OR $0.03 ; 95 \%$ CI 0.01 to 0.14 ). Compared with adults with a primary school education or less, adults with a high school education were more likely to be waterpipe smokers (OR 1.87; 95\% CI 1.05 to 3.34). Compared with adults in the lowest income quartile, those in the second (OR 2.50; 95\% CI 1.19 to 5.26) and third (OR 2.45; 95\% CI 1.13 to 5.30) quartiles were more likely to be current waterpipe smokers.

In Jordan, males were more likely than females to be current waterpipe smokers (OR 1.92; 95\% CI 1.40 to 2.62). Compared with adults $18-29$ years old, older adults were less likely to be waterpipe smokers: (OR 0.66; $95 \%$ CI 0.44 to 0.99 ) among those $30-49$ years old, (OR 0.45 ; $95 \%$ CI 0.27 to 0.75$)$ among those $50-64$ years old and (OR $0.07 ; 95 \%$ CI 0.02 to 0.31 ) among those $\geq 65$ years old.

Similarly, in Palestine, males were more likely than females to be current waterpipe smokers (OR 2.69; $95 \%$ CI 1.85 to 3.92). Compared with adults 18-29 years old, older adults were less likely to be waterpipe smokers: (OR $0.48 ; 95 \%$ CI 0.30 to 0.77 ) among adults $30-49$ years old
(OR $0.19 ; 95 \%$ CI 0.09 to 0.35 ) among adults $50-64$ years old and (OR $0.19 ; 95 \%$ CI 0.05 to 0.77 ) among adults $\geq 65$ years old.

\section{DISCUSSION}

This study provides contemporary estimates of the prevalence and patterns of cigarette and waterpipe smoking among adults in Lebanon, Jordan and Palestine using nationally representative surveys. Findings from the study raise renewed concerns over tobacco use in these countries, which have some of the highest smoking prevalence rates globally: more than two in three adults in Lebanon are current smokers of combustible tobacco products, and almost two-thirds of adult males in Jordan and Palestine are also current smokers. Generally, males were more likely to be current smokers than females. However, almost half of adult females were current waterpipe smokers in Lebanon, exceeding by $40 \%$ the prevalence among adult males in that country.

Our study showed comparable results to previously reported prevalence estimates of current cigarette smoking in Lebanon. We report slightly higher estimates 
Table 5 Multivariable analysis of factors associated with current waterpipe smoking among adults by country in 2019

\begin{tabular}{|c|c|c|c|c|c|c|}
\hline \multirow[b]{2}{*}{ Variable } & \multicolumn{2}{|l|}{ Lebanon } & \multicolumn{2}{|l|}{ Jordan } & \multicolumn{2}{|l|}{ Palestine } \\
\hline & Adjusted OR (95\% CI) & $P$ value & Adjusted OR (95\% CI) & $P$ value & Adjusted OR (95\% Cl) & $P$ value \\
\hline \multicolumn{7}{|l|}{ Gender } \\
\hline Male & 0.49 (0.37 to 0.64$)$ & $<0.001$ & 1.92 (1.40 to 2.62$)$ & $<0.001$ & 2.69 (1.85 to 3.92$)$ & $<0.001$ \\
\hline \multicolumn{7}{|l|}{ Age, in years } \\
\hline $50-64$ & 0.08 (0.04 to 0.15$)$ & $<0.001$ & 0.45 (0.27 to 0.75$)$ & 0.02 & 0.19 (0.09 to 0.35$)$ & $<0.001$ \\
\hline$\geq 65$ & 0.03 (0.01 to 0.14$)$ & $<0.001$ & 0.07 (0.02 to 0.31$)$ & $<0.001$ & 0.19 (0.05 to 0.77$)$ & 0.02 \\
\hline \multicolumn{7}{|l|}{ Education } \\
\hline Primary school or less & Reference & & Reference & & Reference & \\
\hline \multicolumn{7}{|l|}{ Marital status } \\
\hline Not married & Reference & & Reference & & Reference & \\
\hline Married & 1.54 (0.91 to 2.63$)$ & 0.11 & $1.06(0.71$ to 1.58$)$ & 0.76 & 0.66 (0.41 to 1.06$)$ & 0.08 \\
\hline \multicolumn{7}{|l|}{ Monthly income* } \\
\hline Quartile 1 & Reference & & Reference & & Reference & \\
\hline Quartile 2 & 2.50 (1.19 to 5.26$)$ & 0.02 & $0.75(0.49$ to 1.14$)$ & 0.18 & 0.71 (0.43 to 1.18$)$ & 0.18 \\
\hline Quartile 3 & 2.45 (1.13 to 5.30$)$ & 0.02 & 1.05 (0.67 to 1.66$)$ & 0.82 & 0.89 (0.49 to 1.61$)$ & 0.50 \\
\hline Quartile 4 & $1.93(0.79$ to 4.74$)$ & 0.15 & $1.44(0.87$ to 2.37$)$ & 0.16 & 1.20 (0.66 to 2.20$)$ & 0.66 \\
\hline No income & 1.27 (0.28 to 5.84$)$ & 0.76 & 1.01 (0.37 to 2.75$)$ & 0.98 & 0.72 (0.22 to 2.37$)$ & 0.22 \\
\hline
\end{tabular}

*Income quartile levels: Lebanon: (1) <US\$529.88; (2) US\$529.88 to < US\$993.53; (3) US\$993.53 to <US\$1987.05; (4) $\geq$ US $\$ 1987.05$. Jordan: (1)_<US\$423.13; (2) US\$423.13 = <US\$705.22; (3) US\$705.22 to <US\$1269.39. Palestine: (1) <US\$610.04; US\$610.04 to <US\$1067.57; (3) US $\$ 1067.57$ to <US\$1525.10; (4) $\geq 1525.10$.

for males and females compared with the most recent published estimates where the rates of current cigarette smoking for males and females was $34 \%$ and $19 \%$, respectively. ${ }^{2}$ As for waterpipe tobacco smoking, our study reports a higher prevalence particularly among females when compared with the latest reported rate of $24.3 \% .^{16}$ This may be partially explained by the fact that waterpipe smoking is increasingly becoming a socially normative behaviour and remains poorly unregulated, widely available and affordable in Lebanon. ${ }^{21}$

In Jordan, our prevalence estimate of current smoking of any tobacco products among men $(50.1 \%)$ was lower than the previously reported rate $(65.3 \%)$ in the STEP 2019. ${ }^{17}$ Among Jordanian women, our estimate (15.9\%) was consistent with the STEP 2019 estimate (16.4\%). ${ }^{17}$ In Palestine, adult prevalence estimates of cigarette smoking among males were markedly higher than previously reported estimates of $49.7 \%$, while for females it was relatively similar, $3.5 \% .{ }^{18}$ We compare here our findings with previously reported prevalence rates in the three countries, bearing in mind that the methodologies of cited studies might not be comparable. ${ }^{216-1821}$

The gender-specific and age-specific prevalence rates of cigarette and waterpipe tobacco smoking are generally consistent with previous findings in the three countries. ${ }^{3}$ Females in Lebanon had the highest prevalence of waterpipe smoking whereas males in Palestine had the highest prevalence of cigarette smoking across the three countries. Young adults across all three countries were more likely to smoke waterpipe tobacco in line with previous reports that waterpipe smoking has become widespread among young adults which is also consistent with reported global trends. ${ }^{41422} 23$ This may be attributable to the fact that waterpipe smoking is widely perceived to be less harmful than cigarette smoking among young people. ${ }^{6}$

Patterns of smoking were different among current cigarette smokers across the three countries. More than onethird of males and females in Lebanon were light smokers, averaging less than ten cigarettes per day. In contrast, only $3.4 \%$ of males and $18.0 \%$ of females who were current cigarette smokers in Jordan were light smokers. Similarly, in Palestine, $9.4 \%$ of males and $23.1 \%$ of females were light smokers. These patterns, combined with the high overall prevalence rates of cigarette smoking, may be suggestive that for a significant proportion of smokers, cigarette smoking may be regarded more as a social behaviour, especially in Lebanon. Alternatively, almost all male smokers in Jordan were heavy smokers, suggesting 
higher levels of addiction, with relevant implications for improving the use of existing smoking cessation services in Jordan. ${ }^{22}$

Finally, it is important to highlight that across all three countries, the overwhelmingly majority of current waterpipe smokers use flavoured tobacco, as previously reported in other countries in the EMR. In a study by Hamadeh $e t a l^{24}$ out of the 2470 students that participated in the study from Egypt, Jordan, Palestine and the United Arab Emirates, the majority of male and female students smoked flavoured waterpipe tobacco. ${ }^{24}$ This was also observed in Iran where $56 \%$ of smokers used flavoured waterpipe tobacco. ${ }^{25}$ This pattern may be attributed to increased availability of flavoured tobacco products, affordability, their unregulated marketing, as well as poor and often misleading labelling ${ }^{5}$ calling for the need to consider banning of flavouring in tobacco as a potentially strong regulatory measure. ${ }^{26}$

Strengths of this study include the fact that it reports contemporary estimates of smoking prevalence using large, nationally representative surveys, that have been consistently lacking in previous studies. The study used standardised questionnaires across the three countries, allowing for valid cross-country comparisons. Study limitations include the fact that tobacco use was self-reported and not biochemically verified, which may under-report prevalence. In addition, only a small number of females reported current smoking in Jordan and Palestine. These small sample sizes may have resulted in unreliable estimates of the detailed patterns of cigarette and waterpipe smoking reported for females in the two countries. The study also did not report on use of other alternative smoking products such as electronic cigarettes, ${ }^{1727}$ heated tobacco and midwakh, ${ }^{28}{ }^{29}$ which are increasingly more available in the loosely regulated markets of those countries.

\section{CONCLUSION}

The prevalence of tobacco smoking is alarmingly high in Lebanon, Jordan and Palestine. The age-standardised prevalence rates of current cigarette and waterpipe smoking were $27.8 \%$ and $38.1 \%$ in Lebanon, $25.5 \%$ and $12.0 \%$ in Jordan, and $26.3 \%$ and $14.1 \%$ in Palestine. These high estimates highlight the immediate need to strengthen existing tobacco control policies, especially those that address waterpipe tobacco smoking. Regulations should address waterpipe tobacco smoking in relation to all articles of the FCTC and should also be informed by the body of research in Lebanon, Jordan and Palestine evaluating waterpipe specific interventions. This should be coupled with regular monitoring of tobacco trends using surveillance data such as the ones reported in this study in order to evaluate progress at national level. Findings from this research provide policymakers with evidence that can support them in calling for improved policies and measures to curb tobacco use.

\section{Author affiliations}

'Department of Health Promotion and Community Health, Faculty of Health Sciences, American University of Beirut, Beirut, Lebanon

${ }^{2}$ Department of Community Medicine, Public Health and Family Medicine, Faculty of Medicine, Jordan University of Science and Technology, Irbid, Jordan

${ }^{3}$ Department of Agriculture, Faculty of Agricultural and Food Sciences, American University of Beirut, Beirut, Lebanon

${ }^{4}$ Institute of Community and Public Health, Birzeit University, Birzeit, Palestine ${ }^{5}$ Department of Community, Environmental and Occupational Medicine, Ain Shams University Faculty of Medicine, Cairo, Egypt

${ }^{6}$ Public Health Policy Evaluation Unit, Imperial College London School of Public Health, London, UK

${ }^{7}$ Department of Biostatistics and UF Health Cancer Center, University of Florida, Gainesville, Florida, USA

${ }^{8}$ Department of Health Outcomes and Biomedical Informatics, University of Florida College of Medicine, Gainesville, Florida, USA

Twitter Rima Nakkash @rimanakkash, Ali Chalak @AliChalak3, Ruba Abla @ RubaAbla, Niveen M E Abu-Rmeileh @Niveen18, Mohammed Jawad @mojawad606 and Ramzi G Salloum @ramzi_salloum

Contributors RN, RGS and YK led the study design. RN, YK and NMEA-R monitored data collection. YK, MJ and AC were responsible for data analysis. RN, RA and RGS wrote the first draft. YK, AC, NMEA-R, MJ, AM and J-HL contributed to successive drafts. All authors approved the final manuscript. RN is responsible for the overall content as the guarantor.

Funding This study was funded by the International Development Research Centre (Grant number 108821).

Disclaimer The funding agency played no role in study design, in the collection, analysis and interpretation of data, in the writing of the report and in the decision to submit the article for publication. The content is solely the responsibility of the authors and does not necessarily represent the official views of the funding agency. Competing interests None declared.

Patient consent for publication Not applicable.

Ethics approval This study was approved by the International Review Board at the American University of Beirut.ID number: SBS-2019-0097.

Provenance and peer review Not commissioned; externally peer reviewed.

Data availability statement Data are available on reasonable request.

Supplemental material This content has been supplied by the author(s). It has not been vetted by BMJ Publishing Group Limited (BMJ) and may not have been peer-reviewed. Any opinions or recommendations discussed are solely those of the author(s) and are not endorsed by BMJ. BMJ disclaims all liability and responsibility arising from any reliance placed on the content. Where the content includes any translated material, BMJ does not warrant the accuracy and reliability of the translations (including but not limited to local regulations, clinical guidelines, terminology, drug names and drug dosages), and is not responsible for any error and/or omissions arising from translation and adaptation or otherwise.

Open access This is an open access article distributed in accordance with the Creative Commons Attribution Non Commercial (CC BY-NC 4.0) license, which permits others to distribute, remix, adapt, build upon this work non-commercially, and license their derivative works on different terms, provided the original work is properly cited, appropriate credit is given, any changes made indicated, and the use is non-commercial. See: http://creativecommons.org/licenses/by-nc/4.0/.

\section{ORCID iDs}

Ruba Abla http://orcid.org/0000-0002-0629-5351

Aya Mostafa http://orcid.org/0000-0002-2803-2608

Mohammed Jawad http://orcid.org/0000-0002-1051-2136

Ramzi G Salloum http://orcid.org/0000-0002-8139-2418

\section{REFERENCES}

1 WHO. WHO report on the global tobacco epidemic. 2021: addressing new and emerging products, 2021.

2 WHO. WHO global report on trends in prevalence of tobacco smoking 2000-2025. World Health Organization, 2018.

3 Maziak W, Nakkash R, Bahelah R, et al. Tobacco in the Arab world: old and new epidemics amidst policy paralysis. Health Policy Plan 2014;29:784-94. 
4 Akl EA, Gunukula SK, Aleem S, et al. The prevalence of waterpipe tobacco smoking among the general and specific populations: a systematic review. BMC Public Health 2011;11:244.

5 Maziak W, Taleb ZB, Bahelah R, et al. The global epidemiology of waterpipe smoking. Tob Control 2015;24 Suppl 1:i3-12.

6 Akl EA, Ward KD, Bteddini D, et al. The allure of the waterpipe: a narrative review of factors affecting the epidemic rise in waterpipe smoking among young persons globally. Tob Control 2015;24 Suppl 1:i13-21.

7 Salloum RG, Nakkash R, Abu-Rmeileh NME, et al. Individual-Leve determinants of waterpipe smoking demand in four EasternMediterranean countries. Health Promot Int 2019;34:1157-66.

8 WHO. WHO report on the global tobacco epidemic, 2008: the MPOWER package. Geneva, Switzerland: World Health Organization, 2008.

9 WHO. Global adult tobacco survey: Egypt country report 2009, 2009

10 WHO. Global adult tobacco survey: Qatar country report 2013, 2013.

11 WHO. Global adult tobacco survey: Pakistan country report 2014 2014.

12 Jawad M, Lee JT, Millett C. Waterpipe tobacco smoking prevalence and correlates in 25 eastern Mediterranean and eastern European countries: cross-sectional analysis of the global youth tobacco survey. Nicotine Tob Res 2016;18:395-402.

13 Salloum RG, Lee J, Mostafa A, et al. Waterpipe tobacco smoking among university students in three eastern Mediterranean countries: patterns, place, and price. Subst Use Misuse 2019;54:2275-83.

14 Hamadeh RR, Lee J, Abu-Rmeileh NME, et al. Gender differences in waterpipe tobacco smoking among university students in four eastern Mediterranean countries. Tob Induc Dis 2020;18:1-12.

15 Merrill RM, Madanat $\mathrm{H}$, Kelley AT. Smoking prevalence, attitudes, and perceived smoking prevention and control responsibilities and practices among nurses in Amman, Jordan. Int J Nurs Pract 2010;16:624-32.

16 Sibai A, Tohme R, Mahfoud Z. Non-Communicable diseases and behavioral risk factor survey: comparison of estimates based on cell phone interviews with face to face interviews. WHO Lebanon office Beirut, Lebanon: Final report submitted to World Health Organization-Lebanon office, 2009.
$17 \mathrm{MoH}$. Jordan national stepwise (steps) survey for non-communicable disease risk factors. Jordan, 2019.

18 Palestinian Bureau of Statistics. Palestinian family survey 2010. monitoring the situation of children and women. UNICEF, UNFPA 2013.

19 Abdulrahim S, Jawad M. Socioeconomic differences in smoking in Jordan, Lebanon, Syria, and Palestine: a cross-sectional analysis of national surveys. PLoS One 2018;13:e0189829.

20 Ahmad OB, Boschi-Pinto C, Lopez AD. Age standardization of rates: a new who standard. 9. Geneva: World Health Organization, 2001.

21 Daou KN, Bou-Orm IR, Adib SM. Factors associated with waterpipe tobacco smoking among Lebanese women. Women Health 2018;58:1124-34.

22 Jaghbir M, Shareif S, Ahram M. Quitting smoking and utilization of smoking cessation services in Jordan: a population-based survey. East Mediterr Health J 2014;20:538-46.

23 Khattab A, Javaid A, Iraqi G, et al. Smoking habits in the middle East and North Africa: results of the breathe study. Respir Med 2012;106 Suppl 2:S16-24

24 Hamadeh RR, Borgan SM, Khabsa J, et al. Tobacco research in the eastern Mediterranean region: a scoping review of published studies from seven countries. J Community Health 2021;46:225-31.

25 Ebrahimi Kalan M, Abazari M, Ben Taleb Z, et al. Characteristics of flavored and non-flavored waterpipe tobacco users: a real-world setting study. Environ Sci Pollut Res Int 2021;28:57629-39.

26 Yang $Y$, Lindblom EN, Salloum RG, et al. The impact of a comprehensive tobacco product flavor ban in San Francisco among young adults. Addict Behav Rep 2020;11:100273.

27 Aghar H, El-Khoury N, Reda M, et al. Knowledge and attitudes towards e-cigarette use in Lebanon and their associated factors. BMC Public Health 2020;20:1-18.

28 Nakkash RT, El Boukhari N, Afifi RA. 'When I smoked it, it was like a slap in the face but it felt really good': exploring determinants of midwakh use among young adults in Lebanon. Tob Control 2021;30:351-5

29 Afifi R, Saravanan M, El Salibi N, et al. Evidence from the Lebanon global school-based student health survey on midwakh tobacco smoking in school students: a harbinger of the next global tobacco pandemic? East Mediterr Health J 2020;26:116-21. 